\title{
A reconfiguração da indústria da música
}

\section{Marcelo Kischinhevsky e Micael Herschmann}

\section{Resumo}

0 presente trabalho busca mapear as principais transformações nos negócios musicais - fonográficos e da música ao vivo - ocorridas ao longo da última década, com a prevalência das Novas Tecnologias de Informação e Comunicação e as tentativas de reposicionamento da antiga indústria fonográfica. Em contraponto à profusão de sistemas de compartilhamento de arquivos digitais de áudio via internet, sem custo para o usuário, emergem novos canais de vendas, entre os quais destacam-se a telefonia móvel, os jogos eletrônicos e as mídias sociais de base radiofônica. Discutiremos como se redesenham as relações entre companhias musicais e consumidores a partir destas inovadoras estratégias de visibilidade adotadas por empresários, produtores e artistas - estratégias que privilegiam o acesso à música, num mercado sob pressão devido à commoditização do fonograma e no qual se revalorizam as apresentações ao vivo.

\section{Palavras-chave:}

Indústria da Música. Telefones Celulares. Videogames. Mídias Sociais de Base Radiofônica

\section{Marcelo Kischinhevsky I marcelokisch@gmail.com}

Doutor em Comunicação e Cultura pela Escola de Comunicação da Universidade Federal do Rio de Janeiro (ECO/UFRJ). Professor e pesquisador do Departamento de Jornalismo e do Programa de PósGraduação em Comunicação da Faculdade de Comunicação Social da Universidade do Estado do Rio de Janeiro (FCS/UERJ).

Micael Herschmann I micaelmh@globo.com

Doutor em Comunicação e Cultura pela Escola de Comunicação da Universidade Federal do Rio de Janeiro (ECO/UFRJ). Professor e pesquisador do Programa de Pós-Graduação em Comunicação e Cultura e coordenador do Núcleo de Estudos e Projetos em Comunicação (NEPCOM) da ECO/UFRJ.

\section{Introdução}

A proliferação das tecnologias digitais tornou a música onipresente, trilha sonora do dia-a-dia, fruída em dispositivos portáteis e nos meios de comunicação tradicionais (rádio, TV), na internet, na telefonia móvel, em jogos eletrônicos, nos escritórios, nos elevadores, nas ruas, nas lojas de comércio varejista. Nunca a música esteve tão acessível, mas também jamais foi tão difícil estabelecer o seu valor de troca, num mercado de bens simbólicos, hoje caracterizado pela superoferta de commodities culturais.

Neste artigo, busca-se traçar um panorama da reconfiguração dos negócios da música fonográficos e ao vivo - e como essas mudanças vêm redesenhando o consumo. Articulam-se reflexões de autores ligados aos Estudos Culturais, bem como à Economia Política da Comunicação, que proporcionam instrumental de análise para investigarmos este destacado segmento das indústrias culturais.

Evitamos aqui cair nas tentadoras análises de viés tecnológico, que propalam uma suposta 
democratização inerente ao processo de digitalização das indústrias da cultura e da comunicação. Preocupam-nos, especificamente, os impactos da presente reordenação da indústria da música sobre a diversidade cultural, ameaçada pelas dificuldades enfrentadas por artistas independentes no acesso às redes de distribuição controladas pela grande indústria e na negociação com novos intermediários.

0 presente artigo também sintetiza reflexões desenvolvidas ao longo da disciplina intitulada Indústria da Música como laboratório da Economia da Cultura emergente, oferecida pelos autores aos alunos do Programa de PósGraduação em Comunicação da Escola de Comunicação da Universidade Federal do Rio de Janeiro (ECO/UFRJ), no primeiro semestre de 2010. Ambos agradecem ao Conselho Nacional de Desenvolvimento Científico e Tecnológico (CNPq) e à Fundação Carlos Chagas Filho de Amparo à Pesquisa do Estado do Rio de Janeiro (Faperj) pelo apoio às suas pesquisas.

\section{Cadeias produtivas, circuitos e cenas musicais}

Desde 1997, assistimos a um processo de reconfiguração da indústria da música mundial. Presenciamos mudanças significativas na estrutura da sua cadeia produtiva: constatamos com grande perplexidade, por exemplo, a redução do cast de artistas e do quadro de funcionários das grandes empresas; a crise da noção de álbum (vários músicos vêm repensando a relevância de gravá-los e/ou lançá-los) que vai deixando de ser o objetivo central nessa indústria ou a mercadoria mais valorizada nessa dinâmica de produção e consumo; 0 desaparecimento de antigas funções na cadeia (como a de compositor não-intérprete) e, ao mesmo tempo, o surgimento de novas profissões articuladas a este setor (várias delas ligadas às novas tecnologias digitais); e assim por diante. Em função do ineditismo dessas mudanças, poder-se-ia dizer que a indústria da música, em certo sentido, constitui-se em uma espécie de "laboratório" para observar as transformações que já estão começando a afetar os diferentes setores das indústrias culturais (BUSTAMANTE, 2002; HERSCHMANN, 2010a, 2010b, 2010c).

Evidentemente, para compreender melhor a nova conformação da música, é preciso inseri-la no contexto de processos produtivos regidos por lógicas econômicas. Para Prestes Filho (2004, p. 29), a

[...] cadeia produtiva da economia da música é um complexo híbrido, constituído pelo conjunto de atividades industriais e serviços especializados que se relacionam em rede, complementando-se num sistema de interdependência para consecução de objetivos comuns artístico, econômico e empresarial.

Esta cadeia produtiva é integrada por circuitos culturais, que se formam na articulação entre cenas artísticas locais e empresas do setor de comunicação e cultura (selos musicais, redes de rádio e TV, imprensa especializada), além de produtores, empresários autônomos e outros 
profissionais que orbitam os negócios da música (DU GAY, 1997).

0 caráter industrial do segmento fonográfico foi objeto de diversos estudos ao longo das últimas décadas, desde a denúncia da estandardização da música popular por Adorno e Horkheimer, passando pelo modelo de "filtros" produtivos delineado por Paul Hirsch e pela "fabricação" dos artistas, mapeada por John Ryan e Richard Peterson num estudo de caso sobre a música country, até a abordagem de Joli Jensen, para quem a cultura não é apenas um produto, algo processado tecnicamente por organizações orientadas por fatores econômicos, mas também meio para que as pessoas construam significados para os mundos em que vivem. ${ }^{1}$

Na realidade, analisando com atenção esta indústria é possível identificar duas faces visíveis dessa enorme avalanche de transformações que estão ocorrendo na indústria da música nos últimos anos: a) primeiramente, presenciamos não só a desvalorização vertiginosa dos fonogramas (sua transformação em commodity no mercado), mas também 0 crescente interesse e valorização da música ao vivo (dos concertos) executada especialmente nos centros urbanos (no universo indie, na maioria das vezes, não constituindo propriamente cadeias produtivas, mas sim "cenas" ou "circuitos", muitas vezes legitimados na celebração de festivais); b) e, em segundo lugar, a busca desesperada por novos modelos de negócio fonográficos (que hoje emergem na forma de diferentes tipos de plataformas digitais e nos serviços da telefonia móvel), ou melhor, 0 crescente emprego das novas tecnologias e das redes sociais na web como una forma importante de reorganização do mercado - a utilização das tecnologias em rede como uma relevante estratégia de comunicação e circulação de conteúdos, de gerenciamento de carreiras artísticas, de formação e renovação de público, de construção de alianças com os consumidores etc. (HERSCHMANN, 2010a, 2010b, 2010c).

É importante fazer uma diferenciação conceitual entre cenas, circuitos culturais (musicais) e cadeias produtivas, pois estas noções são muito empregadas para qualificar o universo da música. Segundo Freire Filho e Marques (2007), as "cenas" seriam mais fluidas, instáveis e nelas seria possível atestar um maior protagonismo dos atores sociais. As cenas dependeriam de identificações, afetividades e alianças construídas entre os indivíduos. Segundo esses autores, seria possível se afirmar que existiria na cena mais persistência do que propriamente uma rebeldia subcultural. No caso dos "circuitos culturais", estes seriam menos fluidos que as cenas. Segundo Herschmann (2007), haveria nos circuitos culturais níveis de institucionalidade, isto é a dinâmica deles seria de certa forma híbrida: muitas vezes encontraríamos circuitos territorializados (mas não necessariamente 
vinculados a um território), contudo ainda se identificaria um razoável protagonismo dos atores sociais. ${ }^{2}$

Já as "cadeias produtivas" teriam uma dinâmica institucionalizada (os atores sociais portanto, nas cadeias produtivas, não estão mais no "terreno da informalidade"). As cadeias produtivas estariam fundadas, portanto, segundo boa parte da literatura de economia da cultura, em contratos de trabalho; 0 protagonismo dos atores sociais encontra-se em articulação e tensão com regras/normas impessoais e preestabelecidas; podem estar construídas em várias escalas (locais, nacionais, transnacionais); se definem como conjunto de atividades que se articula progressivamente, desde os insumos básicos até 0 produto/serviço final (incluindo as etapas de distribuição e comercialização), constituindo-se assim em elos de uma corrente (HERSCHMANN, 2010a).

Evidentemente, não há produção musical contemporânea desvinculada de processos industriais (de perfis mais tradicionais), embora a inserção dos artistas nesse mercadomundo seja variável - a indústria investe em determinados gêneros, enquanto outros são postos (ou se colocam deliberadamente) à margem. Na última década, no entanto, a forma como a produção cultural se organiza sofreu uma série de transformações.
Tomando-se os elos da cadeia produtiva caracterizados por Prestes Filho (2004), percebese que a reordenação dos negócios da música ao longo dos últimos anos trouxe impacto sobre a pré-produção (fabricação de instrumentos, equipamentos de som e gravação), a produção (criação/composição, estúdios, técnicas de gravação, mixagem, masterização etc.), distribuição (logística, divulgação/promoção, em rádio, TV, internet, shows), comercialização (lojas - em franco declínio - e outros pontos de vendas, como supermercados, livrarias, bancas de jornais, serviços de download pago) e consumo (rádio, TV, internet, shows, equipamentos de som, cinema, teatro, festas, bares, boates, estabelecimentos comerciais).

As Novas Tecnologias de Informação e Comunicação (NTICs) baratearam 0 custo de pré-produção e produção, acoplando instrumentos eletrônicos a computadores e softwares de edição. Estúdios caseiros simplificaram o registro do trabalho de artistas, embora a masterização permaneça um gasto elevado, acima das possibilidades financeiras da maioria, formando na prática uma barreira à entrada no mercado de novos músicos.

Apesar da perda de participação das multinacionais do disco, com a emergência de selos independentes locais (de maior ou menor porte) nos principais mercados 
nacionais, os canais de distribuição permanecem dominados por estas majors. A articulação da grande indústria fonográfica com os meios de comunicação, notadamente o rádio, que tem nas verbas de promoção (leia-se jabá) uma de suas principais fontes de faturamento, alija do mercado players de menor porte, condenados a explorar nichos considerados pouco rentáveis pelos gigantes do setor.

\section{A comercialização tornou-se 0 calcanhar-de-} aquiles da indústria, que vem denunciando em sucessivos relatórios setoriais o fechamento de milhares de lojas de discos e a proliferação de serviços de download gratuito de arquivos musicais - uma alternativa de divulgação para artistas independentes que buscam um lugar ao sol, mas considerados ilegais pelas majors, que vêm sendo bem-sucedidas, em diversos países, em sua cruzada para criminalizar o compartilhamento de música on-line. Pressionadas pela perda de faturamento, cada vez mais as gigantes do setor apostam em canais alternativos de vendas. Telefones celulares e jogos eletrônicos, que não estavam sequer listados nos elos da cadeia produtiva mapeada há seis anos por Prestes Filho, tornaram-se importantes fontes de receitas.

Estes novos canais também vêm ajudando a moldar relações de consumo musical. A proliferação de dispositivos digitais individuais (telefones celulares, tocadores multimídia) engendra uma cultura da portabilidade (KISCHINHEVSKY, 2009), que franqueia não só o consumo de arquivos musicais, mas também a produção, proporcionando o registro de apresentações ao vivo por fãs de artistas, que depois postam áudios e vídeos na internet, amplificando seu alcance, ou mesmo apoiando o processo criativo de jovens músicos - não são poucos os artistas que usam hoje o celular para gravar e armazenar esboços de melodias a serem desenvolvidas, posteriormente, em canções.

A velha indústria fonográfica entrou no mercado digital com forte atraso, mas já colhe os frutos dos investimentos recentes e da política de criminalização dos serviços de compartilhamento de arquivos de áudio. As vendas digitais totalizaram US $\$ 4,2$ bilhões em 2009, em todo o mundo, segundo o último Digital Report, da International Federation of Phonographic Industry (IFPI). Este montante já representa $27 \%$ do faturamento total do segmento, contra praticamente zero apenas seis anos atrás.

Ainda de acordo com o relatório, 11 milhões de fonogramas foram licenciados para cerca de 400 serviços dos mais diversos países.

A política mais recente das velhas indústrias fonográficas, que hoje tentam se reinventar como "companhias musicais", é, em muitos casos, franquear 0 acesso a seus acervos por meio de parcerias com novos intermediários - operadoras de telefonia móvel, fabricantes de telefones celulares e tocadores multimídia, provedores de internet, mídias sociais de base radiofônica, grandes varejistas on-line, portais 
(jornalísticos ou não) que detêm soluções inovadoras em comércio eletrônico etc. Desta forma, buscam retomar as rédeas de um mercado onde, nos últimos 15 anos, o preço do fonograma vem declinando ininterruptamente e no qual a música pop vem se tornando uma commodity, um produto negociado muitas vezes a poucos centavos, bônus na compra de outros artigos, como telefones celulares.

\section{Emergência de negócios fonográficos}

Como é amplamente sabido, diante das novas tecnologias digitais, a indústria da música passou a enfrentar sérios problemas para conciliar as novas práticas de distribuição e consumo de fonogramas com a tradicional estrutura de comércio de música gravada que existia: a retração de aproximadamente $30 \%$ do mercado nos últimos cinco anos indica que estas dificuldades não foram superadas. Contudo, é possível constatar a emergência de novas estratégias das grandes empresas, que passaram a investir pesadamente na reintermediação da web: não só na formação de parcerias com sites e plataformas que mobilizam de forma eficiente as grandes redes sociais da internet, mas também realizando investimentos em licenças para comercializar conteúdos que visam se traduzir na ampliação de seus catálogos (DE MARCHI; ALBORNOZ; HERSCHMANN, 2010). Assim, além da telefonia móvel; de vendas offline em estações digitais que parecem caixas eletrônicos, dos inúmeros tipos de lojas digitais online que existem em todo 0 mundo e que vendem fonogramas de forma avulsa ou oferecem o serviço de assinatura de seu banco digital; e das plataformas de videogames musicais; começam a surgir também de forma crescente sites de compartilhamento de arquivos (peer-topeer, ou P2P) autorizados, os quais estabelecem com as gravadoras não só acordos para abrir parte dos conteúdos musicais, mas também acordos financeiros para pagamentos de copyright, mesmo que a preços mais acessíveis.

As vendas de arquivos digitais de áudio vinham sendo puxadas desde 0 início no Brasil pelos serviços de download oferecidos pelas operadoras de telefonia móvel. Este cenário foi alterado com 0 avanço dos negócios digitais da internet. A música baixada no celular chegou a representar cerca de $80 \%$ do faturamento das companhias fonográficas no Brasil, no segmento digital. 0s dois grandes atores nesse nicho têm sido a finlandesa Nokia - maior fabricante mundial de telefones móveis, com 450 milhões de aparelhos vendidos a cada ano - e a jointventure nipo-sueca Sony Ericsson. Ambas vêm utilizando 0 acesso gratuito a catálogos musicais licenciados pelas grandes gravadoras para impulsionar as vendas de aparelhos de determinados modelos (naturalmente, mais caros do que os demais). ${ }^{3}$ 
Estas estratégias representam uma expansão do mercado formal de música digital, operando como uma espécie de pedagogia do consumo. 0 retorno para os artistas que têm seus fonogramas licenciados, no entanto, é irrisório em termos financeiros, embora ocasionalmente seja positivo como ação de divulgação. Cumpre ressaltar ainda 0 fato de que 0 telefone celular tem se tornado um importante dispositivo para o consumo de conteúdos radiofônicos entre jovens, conforme recente pesquisa (FERRARETTO et al., 2010). ${ }^{4}$

0s resultados destas estratégias começaram a aparecer de forma significativa a partir de 2009 . Nos principais relatórios da indústria, divulgados este ano, anuncia-se um quadro mais promissor: os números oficiais relativos ao faturamento de 2009 apresentaram uma melhora significativa. № mundo, o segmento de consumo de fonogramas digital teve um crescimento de $12 \%$, movimentando cerca de US $\$ 4,2$ bilhões. Assim, o chamado mercado digital gerou no mundo, no ano passado, receitas que representam $27 \%$ do total das vendas de músicas gravadas no globo. No Brasil, a participação dos negócios fonográficos digitais no total das receitas passou de $8 \%$, em 2007, para $12 \%$ em 2008, mantendo-se nesse mesmo patamar em 2009 (IFPI, 2010; ABPD, 2010).

Na verdade, os números do Brasil são bastante expressivos. As vendas de música digital no país cresceram 159,4\%, faturando cerca de $\mathrm{R} \$ 41,7$ milhões. Deste total, $58,7 \%$ ou $\mathrm{R} \$ 25$ milhões, foram de receitas advindas da internet, e 41,3\%, das vendas realizadas através da telefonia móvel (R \$ 17,6 milhões). Pela primeira vez os percentuais das vendas pela internet superaram as vendas realizadas através da telefonia móvel. No Reino Unido, os números de 2009 são ainda mais surpreendentes: pela primeira vez a venda de música digital superou a de CDs. Além disso, apesar de persistir a retração do mercado global, o crescimento das vendas digitais permitiu que 13 mercados voltassem a crescer: entre eles, alguns importantes, tais como Austrália, México, Coréia do Sul e Suécia (IFPI, 2010; ABPD, 2010).

Outro nicho de destaque no consumo de música on-line é o avanço do que chamaremos aqui de mídias sociais de base radiofônica. Pesquisadores vêm divergindo publicamente sobre a possibilidade de que determinados portais e mesmo 0 podcasting sejam abarcados na definição de rádio. Para alguns autores, como Prata (2009), é necessário distinguir entre conteúdos radiofônicos e não-radiofônicos, como playlists personalizáveis ou programas na forma de episódios ouvidos sob demanda. Outros (LEÃO; PRADO, 2007) consideram mais adequado classificar os novos portais como "canais de música em fluxo".

Trabalhamos aqui como uma visão menos restritiva dos conteúdos radiofônicos, por considerarmos que, num ambiente marcado pela 
crescente convergência de mídia, não há como diferenciar substancialmente determinados conteúdos veiculados em Frequência Modulada de outros distribuídos via internet - há emissoras em FM, hoje, que mantêm horários sem locução ao vivo, apenas intercalando vinhetas e músicas; paralelamente, existem programas de linguagem claramente radiofônica, entremeando músicas, locução, vinhetas e até spots publicitários, veiculados na forma de podcasts em diretórios especializados e também distribuídos nestas mídias sociais.

Serviços distintos, como o britânico Last.fm, ${ }^{5}$ 0 americano Blip.fm ${ }^{6}$ e 0 brasileiro Radiotube, ${ }^{7}$ possibilitam a distribuição e 0 consumo de conteúdos radiofônicos e musicais, segundo a lógica de mídias sociais. É possível formar comunidades, estabelecer amizades virtuais, alimentar nuvens de tags, em suma, formular identidades coletivas e individuais através da música e de conteúdos radiofônicos, que formam o elemento-chave de indexação na rede. Alguns permitem 0 download de arquivos, enquanto nos outros só é possível ouvir conteúdos em streaming - estratégia que minimiza o risco de ações judiciais movidas por artistas que venham a alegar uso indevido de fonogramas protegidos por direitos autorais.

Talvez seja um pouco prematuro, mas há indicadores que apontam para tendências de mudança nos hábitos dos consumidores, com uma maior aceitação dos fonogramas legalizados em plataformas autorizadas pelas gravadoras. Seria esta mudança de comportamento resultado: a) de uma mudança no comportamento dos empresários que agora estão dispostos a socializarem significativos lotes de conteúdos?; b) da ampliação da capacidade das intensas campanhas antipirataria em construir um constrangimento moral, um novo imaginário junto aos consumidores?; c) do processo de enclosures na web realizado pelas majors, ou seja, do processo de tomada de controle e fechamento do livre acesso aos conteúdos das plataformas digitais mais populares da internet pelos grandes conglomerados? Esta mudança de comportamento

Endereço: http://lastfm.com.br. Sistema ancorado no programa Audioscrobbler, que lê todos os arquivos do computador do usuário e traça, por meio de algoritmos, uma espécie de perfil, formando sequências de músicas em fluxo contínuo. É possível eleger faixas favoritas, recomendá-las, estabelecer amizades virtuais e ouvir estações de outros usuários livremente. Comprado pelo CBS Interactive Music Group, o portal passou a cobrar por parte de seus serviços, perdendo audiência, mas permanece com milhões de usuários ativos. Mantém escritórios em diversos países, inclusive no Brasil.

Endereço: http://blip.fm. Permite que se distribuam arquivos de áudio, que podem ser ouvidos por um círculo de amigos virtuais do internauta e também numa página pública, visualizada mundialmente. Pode-se fazer comentários sobre os arquivos (musicais e/ ou radiofônicos) e também habilitar o serviço para que suas atualizações sejam recebidas em outras mídias sociais, como Twitter, Facebook e Ping.fm. Não há possibilidade de download. 0 Blip.fm, em sua página inicial, convida os visitantes a se cadastrar prometendo "acesso a milhões de músicas grátis" e a chance de "ter sua própria estação de rádio via internet".

Endereço: http://www.radiotube.org.br. Autoproclamada "rede de cidadania", atende especialmente a organizações ligadas a movimentos sociais, veiculando conteúdo produzido por universidades e ativistas de rádios comunitárias. Conta com mais de 2 mil usuários cadastrados e 179 comunidades on-line. É possível fazer o download dos arquivos, postar comentários e também compartilhá-los por meio de outras mídias sociais, como Twitter, Facebook e Orkut. 
dos consumidores é inquietante, mas ainda serão necessárias pesquisas empíricas para uma avaliação conclusiva.

\section{Emergência de negócios da música ao vivo}

Nos últimos anos, é possível constatar uma relativa mudança na maneira dos artistas especialmente do mainstream - ganharem 0 seu sustento com o crescimento dos concertos ao vivo. Em 2008, o mercado ao vivo teve um crescimento de 10\%, movimentando cerca de US $\$ 25$ bilhões, entre venda de ingressos, publicidade e direitos de imagem. Além disso, se é verdade que até bem pouco tempo os músicos conseguiam dois terços de sua receita através da venda de fonogramas - 0 terço restante era obtido através de shows e publicidade/merchandising -, é preciso ressaltar que atualmente esta proporção se inverteu.

Cientes deste fato, as gravadoras vêm buscando abocanhar este mercado: passaram a adotar, como medida compensatória às suas perdas, alterações dos contratos que impõem aos artistas, prevendo, entre outras coisas, participação nas bilheterias (HERSCHMANN, 2007).

Ao mesmo tempo, analisando o universo da música independente nunca se viram tantos pequenos concertos realizados em diferentes localidades do mundo com novos talentos que emergem da cena local. No Brasil, por exemplo, o mercado de música ao vivo já no início do século XXI seguia a tendência mundial de crescimento. 0 público dos concertos na ocasião era bastante expressivo, sendo estimado em cerca de 42 milhões de pessoas. Poucos indicadores culturais, infelizmente, estão disponíveis sobre 0 crescimento do mercado de concertos. Ao mesmo tempo, torna-se cada vez mais evidente que em diferentes localidades do Brasil vêm emergindo novos circuitos e cenas musicais independentes de expressivo êxito. Poder-seia dar alguns exemplos, tais como o do samba e choro da Lapa (bairro central do Rio de Janeiro), do tecnobrega em Belém, da seresta em Conservatória (localidade do Sul Fluminense), do axé em Salvador ou do forró em Fortaleza (HERSCHMANN, 2010a).

Outro caso que chama a atenção no Brasil hoje é 0 boom dos festivais indies. Com um perfil distinto dos festivais e concertos de música ao vivo promovidos pelas majors com grandes empresas nacionais e transnacionais, vem crescendo significativamente o número de festivais independentes no Brasil. Estes eventos estão organizados por iniciativa de coletivos de artistas, associações, pequenas gravadoras e/ ou produtoras, que mobilizam mais de 300 mil pessoas em cerca de cinco dezenas de festivais regulares por ano que, em geral, são realizados fora das grandes capitais (HERSCHMANN, 2010b). Ainda que muito associado à cena roqueira do país, o circuito de festivais apresenta crescente presença de diferentes conjuntos de redes que envolvem artistas - não só músicos, mas também atores de teatro, acadêmicos, entre outros - e 
diversos nichos de público. Para organizar estes eventos, os produtores desenvolveram algumas estratégias interessantes: utilizam recursos de leis de incentivo à cultura e editais públicos; empregam o potencial interativo das novas tecnologias digitais visando formação, divulgação e mobilização de públicos; praticam intensa militância na área musical e até rotinas que incluem escambo. Assim, diferentemente dos antigos festivais da canção do século passado e dos grandes eventos atualmente realizados no Brasil, pode-se dizer que os novos festivais independentes: 1) usam basicamente mídias alternativas e interativas; 2) reúnem artistas que geralmente não têm vínculos com as grandes empresas; e 3) constituem importantes espaços de consagração e reconhecimento dos músicos dentro do nicho de mercado em que atuam. Em certo sentido, pode-se afirmar que estes coletivos de músicos brasileiros vêm construindo de forma criativa e bem-sucedida novos circuitos de produção-distribuição e consumo culturais (HERSCHMANN, 2010b).

\section{Considerações finais}

A indústria da música se reconfigura, diante das novas tecnologias digitais, mas é cedo para afirmar a sustentabilidade dos novos modelos de negócios que têm emergido. Permanecem preocupações expressivas quanto à capacidade dos músicos se estabelecerem no concorrido mercado de bens simbólicos, em que o fonograma vale cada vez menos e novos intermediários ganham crescente poder de barganha. Países como Brasil, Espanha e França estão entre os que mais registraram retração na oferta de conteúdo local por parte das multinacionais da música ao longo dos últimos anos.

No Brasil, segundo o Digital Report 2010 da IFPI, o lançamento de artistas nacionais pelas majors declinou 80\% entre 2004 e 2009. De acordo com dados da ABPD, a participação de brasileiros entre os lançamentos, que era de $74,5 \%$ em 2008 , recuou para $66 \%$ no ano passado, evidenciando a opção das múltis por música estrangeira, cujo custo de produção já foi diluído pela matriz.

E não há sinais de que o segmento independente tenha capacidade de absorver todos os artistas que estão sendo dispensados pelas gigantes do setor. Sem os antigos investimentos em promoção desembolsados pelas gravadoras, estes músicos muitas vezes perdem espaço nos meios tradicionais e acabam vendo encolher também as possibilidades de faturamento com apresentações ao vivo, atualmente seu principal ganha-pão.

Para 0 consumidor, 0 custo do acesso à música - queixa recorrente nos tempos préinternet - é declinante. Mas a criação artística e a diversidade cultural encontram-se diante de uma série de desafios. Corre-se o risco de concentração empresarial sem precedentes no mercado da música, devido à ascensão de novos intermediários que selam parcerias milionárias com as majors e não remuneram devidamente os artistas. Novas pesquisas, em andamento, deverão 
dar conta desses movimentos, identificando os mecanismos de formação de conglomerados (fusões e aquisições, concorrência predatória, por meio de práticas de dumping etc.); as transformações ocorridas nos elos da cadeia produtiva e no âmbito dos circuitos e das cenas culturais; e as possibilidades de implementação de políticas públicas que assegurem a pluralidade neste estratégico segmento da indústria cultural.

\section{Referências}

ABPD - ASSOCIAÇÃO BRASILEIRA DE PRODUTORES DE DISCOS. Relatório da ABPD 2009/2010. Disponível em: < www.abpd.com.br>. Acesso em: 10 ago. 2010.

BUSTAMANTE, Enrique (Coord.). Comunicación y cultura en la era digital. Barcelona: Gedisa, 2002.

CASTELLS, Manuel et al. Comunicación móvil y sociedad. Barcelona: Ariel, 2007.

DE MARCHI, Leonardo; ALBORNOZ, Luis; HERSCHMANN, Micael. A procura de novos negócios fonográficos: estratégias dos empreendedores brasileiros no mercado de música. In: ENCONTRO ANUAL DOS PROGRAMAS DE PÓS-GRADUAÇÃO EM COMUNICAÇÃO, 19., 2010, Rio de Janeiro. Anais... Rio de Janeiro: Compós, 2010.

DU GAY, Paul etc. (Ed.). Production of culture/

Culture of production. Londres: Sage, 1997.

FERRARETTO, Luiz Artur et al. Rádio, juventude e convergência midiática: um estudo com alunos do ensino médio em Belo Horizonte, Porto Alegre, Rio de Janeiro e São Paulo. In: Congresso Brasileiro de Ciências da Comunicação, 33., 2010, Caxias do Sul. Anais... Caxias do Sul: Intercom, 2010.

\section{FERRARETTO, Luiz; KISCHINHEVSKY,}

Marcelo. Rádio e convergência: uma abordagem pela economia política da comunicação. In: ENCONTRO ANUAL DOS PROGRAMAS DE PÓSGRADUAÇÃO EM COMUNICAÇÃO, 19., 2010, Rio de Janeiro. Anais... Rio de Janeiro: Compós, 2010. FREIRE FILHO, João; MARQUES, Fernanda. Jovens, espaço urbano e identidade: reflexões sobre o conceito de cena musical. In: CONGRESSO BRASILEIRO DE CIÊNCIAS DA COMUNICAÇÃO, 28., 2005. Rio de Janeiro. Anais... Rio de Janeiro: UERJ, 2005.

\section{GALLEGO, Noberto. De amenaza a la} oportunidad: el panorama de la musica on-line. Telos, Madri, n. 63, p. 139-141, abr.jun.2005. Disponível em: http://sociedadinformacion. fundacion.telefonica.com/telos/articulonoticia. asp@idarticulo=5\&rev=63.htm. Acesso em: 5 ago. 2010.

HERSCHMANN, Micael. A indústria da música como laboratório. Revista Observatório Itaú Cultural, São Paulo, n. 9, 2010a. . Crescimento dos festivais de música independente no Brasil. In: SÁ, Simone P. (Org.). Novos rumos da cultura da música. Porto Alegre: Sulinas, $2010 \mathrm{~b}$. 
. Indústria da música em transição. São

Paulo: Estação das Letras e Cores, 2010c.

Alguns apontamentos sobre a

reestruturação da indústria da música. In:

FREIRE FILHO, João; HERSCHMANN, Micael

(Org.). Novos rumos da cultura da mídia. Rio:

Mauad X, 2007.

IFPI - INTERNATIONAL FEDERATION OF

PHONOGRAPHIC INDUSTRY. Digital Report.

Disponível em: <www.ifpi.com>. Acesso em: 10 ago. 2010.

KISCHINHEVSKY, Marcelo. Os portais e a

segmentação no rádio via internet. In: FREIRE

FILHO, João; HERSCHMANN, Micael (Org.).

Novos rumos da cultura da mídia. Rio: Mauad

$\mathrm{X}, 2007$.

LEÃO, Lucia; PRADO, Magaly. Música em fluxo: programas que simulam rádios e a experiência estética em redes telemáticas. Líbero, São Paulo, ano 10, n. 20, p. 69-79, dez. 2007.

NEGUS, Keith. The production of culture. In: DU GAY, Paul et al. (Org.). Production of culture/

Culture of production. Londres: Sage, 1997.

PERPETUO, Irineu; AMADEU, Sergio (Org.). 0

futuro da música depois da morte do CD. São

Paulo: Momento Editorial, 2009.

PRATA, Nair. Webradio: novos gêneros, novas

formas de interação. Florianópolis: Insular, 2009.

PRESTES FILHO, Luiz Carlos (Coord.). Cadeia produtiva da economia da música. Rio de Janeiro: PUC-Rio; Instituto Gênesis, 2004. 


\section{The reconfiguration of music industry}

\section{Abstract:}

This article seeks to map musical business' main changes in the last decade, with prevailing new technologies of communication and information, and old phonographic industry attempts to reposition itself. New sales channels - among which mobile phones, videogames, and radio-based social media get special attention - emerge in a scenario of widespread peer-to-peer, cost free, audio files' sharing systems. New relationships between music companies and consumers will be discussed, as well as visibility strategies adopted by managers, producers, and artists in a market characterized by growing acess to the music, phonogram commoditization, and live concerts revaluation

\section{Keywords:}

Music industry; Mobile phones; Videogames; Radiobased social media

\section{La reconfiguración de la industria de la música}

\section{Resumen:}

El presente artículo intenta esbozar un mapa de las más importantes transformaciones en los negocios de la música - fonográfica y en vivo - ocurridas en la década pasada con la prevalencia de las Nuevas Tecnologías de la Información y la Comunicación y con las estrategías de la vieja indústria fonográfica para reposicionarse. Aunque proliferan los servicios de intercambio de archivos digitales de audio en la internet, sin costo para los usuários, nuevos canales de vendas emergen, dentre los cuales destacanse la telefonía móvil, los juegos electrónicos y las medias sociales basadas en la radiofonia. Se discutirá el rediseño de las relaciones entre compañías musicales y consumidores, desde las inovativas estrategías de visibilidad adoptadas por empresarios, productores y artistas. Estrategías que focalizan el acesso a la música, en un mercado presionado por la commoditization del fonograma y en que revalorizase la música presentada en vivo.

\section{Palabras clave:}

Industria de la música; Teléfonos móviles;

Videojuegos; Medios sociales de base radiofónica 


\section{Expediente}

A revista E-Compós é a publicação científica em formato eletrônico da Associação Nacional dos Programas de Pós-Graduação em Comunicação (Compós). Lançada em 2004, tem como principal finalidade difundir a produção acadêmica de pesquisadores da área de Comunicação, inseridos em instituições do Brasil e do exterior.

\section{E-COMPÓS I www.e-compos.org.br I E-ISSN 1808-2599}

Revista da Associação Nacional dos Programas de Pós-Graduação em Comunicação.

Brasília, v.14, n.1, jan/abr. 2011

A identificação das edições, a partir de 2008

passa a ser volume anual com três números.

\section{CONSELHO EDITORIAL}

Afonso Albuquerque, Universidade Federal Fluminense, Brasil Alberto Carlos Augusto Klein, Universidade Estadual de Londrina, Brasil Alex Fernando Teixeira Primo, Universidade Federal do Rio Grande do Sul, Brasil Ana Carolina Damboriarena Escosteguy, Pontifícia Universidade Católica do Rio Grande do Sul, Brasil

Ana Gruszynski, Universidade Federal do Rio Grande do Sul, Brasil Ana Silvia Lopes Davi Médola, Universidade Estadual Paulista, Brasil André Luiz Martins Lemos, Universidade Federal da Bahia, Brasil Ângela Freire Prysthon, Universidade Federal de Pernambuco, Brasil Angela Cristina Salgueiro Marques, Faculdade Cásper Líbero (São Paulo), Brasil Antônio Fausto Neto, Universidade do Vale do Rio dos Sinos, Brasil Antonio Carlos Hohlfeldt, Pontifícia Universidade Católica do Rio Grande do Sul, Brasil Antonio Roberto Chiachiri Filho, Faculdade Cásper Líbero, Brasil Arlindo Ribeiro Machado, Universidade de São Paulo, Brasil Arthur Autran Franco de Sá Neto, Universidade Federal de São Carlos, Brasil Benjamim Picado, Universidade Federal Fluminense, Brasil César Geraldo Guimarães, Universidade Federal de Minas Gerais, Brasil Cristiane Freitas Gutfreind, Pontifícia Universidade Católica do Rio Grande do Sul, Brasil Denilson Lopes, Universidade Federal do Rio de Janeiro, Brasil Denize Correa Araujo, Universidade Tuiuti do Paraná, Brasil Edilson Cazeloto, Universidade Paulista, Brasil Eduardo Peñuela Cañizal, Universidade Paulista, Brasil Eduardo Vicente, Universidade de São Paulo, Brasi Eneus Trindade, Universidade de São Paulo, Brasil Erick Felinto de Oliveira, Universidade do Estado do Rio de Janeiro, Brasil Florence Dravet, Universidade Católica de Brasília, Brasil Francisco Eduardo Menezes Martins, Universidade Tuiuti do Paraná, Brasil Gelson Santana, Universidade Anhembi/Morumbi, Brasil Gilson Vieira Monteiro, Universidade Federal do Amazonas, Brasil Gislene da Silva, Universidade Federal de Santa Catarina, Brasi Guillermo Orozco Gómez, Universidad de Guadalajara Gustavo Daudt Fischer, Universidade do Vale do Rio dos Sinos, Brasil Hector Ospina, Universidad de Manizales, Colômbia Herom Vargas, Universidade Municipal de São Caetano do Sul, Brasil leda Tucherman, Universidade Federal do Rio de Janeiro, Brasil Inês Vitorino, Universidade Federal do Ceará, Brasil Janice Caiafa, Universidade Federal do Rio de Janeiro, Brasil Jay David Bolter, Georgia Institute of Technology Jeder Silveira Janotti Junior, Universidade Federal de Pernambuco, Brasil João Freire Filho, Universidade Federal do Rio de Janeiro, Brasil
John DH Downing, University of Texas at Austin, Estados Unidos José Afonso da Silva Junior, Universidade Federal de Pernambuco, Brasil José Carlos Rodrigues, Pontifícia Universidade Católica do Rio de Janeiro, Brasil José Luiz Aidar Prado, Pontifícia Universidade Católica de São Paulo, Brasil José Luiz Warren Jardim Gomes Braga, Universidade do Vale do Rio dos Sinos, Brasi Juremir Machado da Silva, Pontifícia Universidade Católica do Rio Grande do Sul, Brasil Laan Mendes Barros, Universidade Metodista de São Paulo, Brasil Lance Strate, Fordham University, USA, Estados Unidos Lorraine Leu, University of Bristol, Grã-Bretanha Lucia Leão, Pontifícia Universidade Católica de São Paulo, Brasil Luciana Panke, Universidade Federal do Paraná, Brasil Luiz Claudio Martino, Universidade de Brasília, Brasil Malena Segura Contrera, Universidade Paulista, Brasil Márcio de Vasconcellos Serelle, Pontifícia Universidade Católica de Minas Gerais, Brasi Maria Aparecida Baccega, Universidade de São Paulo e Escola Superior de Propaganda e Marketing, Brasil

Maria das Graças Pinto Coelho, Universidade Federal do Rio Grande do Norte, Brasil Maria Immacolata Vassallo de Lopes, Universidade de São Paulo, Brasil Maria Luiza Martins de Mendonça, Universidade Federal de Goiás, Brasil Mauro de Souza Ventura, Universidade Estadual Paulista, Brasil Mauro Pereira Porto, Tulane University, Estados Unidos Nilda Aparecida Jacks, Universidade Federal do Rio Grande do Sul, Brasil Paulo Roberto Gibaldi Vaz, Universidade Federal do Rio de Janeiro, Brasil Potiguara Mendes Silveira Jr, Universidade Federal de Juiz de Fora, Brasil Renato Cordeiro Gomes, Pontifícia Universidade Católica do Rio de Janeiro, Brasi Robert K Logan, University of Toronto, Canadá

Ronaldo George Helal, Universidade do Estado do Rio de Janeiro, Brasil Rosana de Lima Soares, Universidade de São Paulo, Brasil Rose Melo Rocha, Escola Superior de Propaganda e Marketing, Brasil Rossana Reguillo, Instituto de Estudos Superiores do Ocidente, Mexico Rousiley Celi Moreira Maia, Universidade Federal de Minas Gerais, Brasil Sebastião Carlos de Morais Squirra, Universidade Metodista de São Paulo, Brasil Sebastião Guilherme Albano da Costa, Universidade Federal do Rio Grande do Norte, Brasil

Simone Maria Andrade Pereira de Sá, Universidade Federal Fluminense, Brasil Tiago Quiroga Fausto Neto, Universidade de Brasília, Brasil Suzete Venturelli, Universidade de Brasilia, Brasil

Valério Cruz Brittos, Universidade do Vale do Rio dos Sinos, Brasil Valerio Fuenzalida Fernández, Puc-Chile, Chile Veneza Mayora Ronsini, Universidade Federal de Santa Maria, Brasil Vera Regina Veiga França, Universidade Federal de Minas Gerais, Brasil

\section{COMISSÃO EDITORIAL}

Adriana Braga I Pontifícia Universidade Católica do Rio de Janeiro, Brasil Felipe Costa Trotta I Universidade Federal de Pernambuco, Brasil CONSULTORES AD HOC

Édison Gastaldo I Universidade Federal Rural do Rio de Janeiro, Brasil Gisela Grangeiro da Silva Castro, Escola Superior de Propaganda e Marketing, Brasil Helio Kuramoto, Instituto Brasileiro de Informação em Ciência e Tecnologia, Brasil Juliano Maurício de Carvalho, Universidade Estadual Paulista, Brasil Maria Helena Weber, Universidade Federal do Rio Grande do Sul, Brasi Paulo Carneiro da Cunha Filho, Universidade Federal de Pernambuco, Brasil Vera Regina Veiga França, Universidade Federal de Minas Gerais, Brasil EDIÇÃO DE TEXTO E RESUMOS I Susane Barros SECRETÁRIA EXECUTIVA I Juliana Depiné EDITORAÇ̃̃o ELETRÔNICA I Roka Estúdio
COMPóS I www.compos.org.br

Associação Nacional dos Programas de Pós-Graduação em Comunicação

Presidente

Itania Maria Mota Gomes

Universidade Federal da Bahia, Brasil

itania@ufba.br

Vice-presidente

Julio Pinto

Pontifícia Universidade Católica de Minas Gerais, Brasil juliopinto@pucminas.br

Secretária-Geral

Ana Carolina Escosteguy

Pontifícia Universidade Católica do Rio Grande do Sul, Brasil carolad@pucrs.br 